\title{
Producción y consumo responsable de alimentos y bebidas en la ciudad de Quito
}

\section{Production and consumption of food and beverages in a responsible way in the city of Quito}

\author{
Diego Alfredo Salazar-Duque \\ Universidad UTE, Quito, Ecuador \\ diegoa.salazar@ute.edu.ec \\ iD https://orcid.org/0000-0003-2111-9134 \\ Elizabeth Carolina Portugal-Morejón \\ Universidad UTE, Quito, Ecuador \\ elizabet.portugal@ute.edu.ec \\ https://orcid.org/0000-0002-8398-4839 \\ Daniel Gonzalo Fierro-Mosquera \\ Universidad UTE, Quito, Ecuador \\ daniel.fierro@ute.edu.ec \\ https://orcid.org/0000-0003-3666-491X
}

Recepción: 05/10/2021 | Aceptación: 05/01/2022 | Publicación: 10/01/2022

Cómo citar (APA, séptima edición):

Salazar-Duque, D. A, Portugal-Morejón, E. C., y Fierro-Mosquera, D. G. (2022). Producción y consumo responsable de alimentos y bebidas en la ciudad de Quito. INNOVA Research Journal, 7(1), 140-165. https://doi.org/10.33890/innova.v7.n1.2022.1965

\section{Resumen}

La producción y el consumo son fuerzas que aportan al impulso económico a nivel mundial que requieren, de manera continua, de varios recursos naturales que se encuentran en el medio ambiente. El uso inadecuado y excesivo de estos pueden generar a futuro efectos destructivos sobre los sistemas de los que depende el desarrollo del planeta. El objetivo de este trabajo fue conocer las acciones que realizan tanto los establecimientos y empresas del sector de servicios de alimentos y bebidas para una producción responsable como del consumo por parte de los consumidores de la ciudad de Quito. Se consideró una investigación cuantitativa con diseño descriptivo y transversal 
donde se levantó dos tipos de encuestas; una dirigida a los establecimientos gastronómicos y otra a los consumidores. Como resultado general se obtuvo que las empresas que se dedican a este servicio generan significativamente actividades relacionadas con las dimensiones ambientales y económicas, y en menor medida a nivel social. En cuanto a los resultados afines con el consumo responsable, un gran porcentaje del mercado conoce los motivos porqué adquiere un producto, pero no los usa o desecha correctamente. Se concluye que, los establecimientos poseen puntos débiles que deben ser ajustados en cuanto a producción, comercio y distribución de sus alimentos y bebidas y para que se genere un consumo responsable es necesario proponer estrategias y acciones que minimice el impacto negativo que puede sufrir el medio ambiente al minimizar el desperdicio, eso quiere decir, aumentar la eficiencia de recursos y promover estilos de vida sostenibles.

Palabras claves: consumo responsable; producción responsable; establecimientos de alimentos y bebidas; Quito.

\begin{abstract}
Production and consumption are forces that encourage an economic development worldwide. They continuously require the use of several natural resources found in the environment. Their inappropriate and excessive use generate destructive effects in the future on the systems on which the development of the planet depends. The aim of this study was to know the actions that were implement by companies in the food and beverage service sector for both responsible production and consumption by clients in Quito. Quantitative research was considered with a nonexperimental, descriptive, and cross-sectional design where two types of surveys were conducted. One addressed at gastronomic establishments and the other at consumers. The establishments which are dedicated to the service of food and beverages significantly generate activities related to the environmental and economic dimensions, and consider actions related to a social level as well. Talking about responsible consumption, a large percentage of the market knows the reasons why they buy a product, but they do not use or dispose of them correctly. It is concluded that these establishments have weak points that need to be adjusted in terms of production, trade and distribution regarding to food and beverages. In the meantime, to generate responsible consumption by a person, it is necessary to implement actions that minimize the negative impact that the environment is suffering by reducing waste. Increasing resource efficiency and promoting sustainable lifestyle will provide a sustainable world in which we live.

Key words: responsible consumption; responsible production; food and beverage establishments; Quito.
\end{abstract}

\title{
Introducción
}

Hoy en día el reconocer, interpretar y elaborar juicios críticos en torno a las sensaciones percibidas del ambiente digital, físico y social (Vargas, 1994), son factores importantes al momento de obtener un producto o un servicio. Es decir, este comportamiento del consumidor, definido por una conducta de compra, el cual tiene su fundamento teórico sobre la base psicológica con enfoque social y conductual (Moscovici, 1988; Robayo, 2010; Bächler, 2017), plantea la existencia de ciertos estímulos que influyen en la decisión final sobre qué, cuánto, dónde y cómo comprar (Hoyer et al., 2015); es decir, el diseño del producto y su apariencia, la mejor forma de adquirirla desde su conveniencia, el precio que debe pagar o si existe alguna promoción que le favorezca económicamente y en cantidad, entre otros son criterios que se miden al momento de 
adquirir un producto, o un servicio (Salazar, 2020). No obstante, en la mayoría de los casos, no se evalúa de dónde provienen los productos, cómo fueron elaborados o transportados, o si aportan o generan beneficios al ser humano, ya sean estos nutricionales, sociales o económicos, o afectan al medio ambiente.

Sobre ese último aspecto, existe y se evidencia, lamentablemente, un gran desperdicio de los alimentos producidos, el consumo inadecuado de energía, y el aumento exponencial de la contaminación del agua. De acuerdo a las Naciones Unidas (s.f.a), por ejemplo, la gran cantidad de alimentos producidos que son desperdiciados por parte de los consumidores y los minoristas terminan pudriéndose en los cubos de basura lo que puede a futuro alcanzar el equivalente a 1300 millones de toneladas; un valor cercano al billón de dólares (Naciones Unidas, s.f.b; United Nations Environment Programme, 2021). Al ser un dato alarmante, se evidencia que ese problema no solo afecta negativamente al medio ambiente, sino también a la economía de una nación.

En ese aspecto, la poca importancia que se puede dar a la manera de cómo se produce o consume un alimento o bebida de forma correcta, que evite el desperdicio, es una variable que debe ser erradicada. Para ello, es necesario concientizar a las personas que, un correcto manejo de los recursos puede contribuir favorablemente al ámbito social, económico y ambiental de un territorio.

Ante esta realidad, las Naciones Unidas en 2015, a través de uno de sus Objetivos de Desarrollo Sostenible (ODS), propone el objetivo 12, "Garantizar modalidades de consumo y producción sostenibles" (Programa de las Naciones Unidas para el Desarrollo, 2021), cuyo principio fundamental se inclina por hacer más y mejor con menos, a partir de ciertas acciones principales que logren: evitar la degradación medioambiental, aumentar la eficiencia de recursos y promover estilos de vida sostenibles (Hernández, 2018) y para ello plantea la meta 3 - "reducir a la mitad el desperdicio de alimentos per cápita mundial en la venta al por menor y a nivel de los consumidores y reducir las pérdidas de alimentos en las cadenas de producción y suministro, incluidas las pérdidas posteriores a la cosecha" (Naciones Unidas, s.f.b). En otras palabras, aquellos estudios que se apeguen a este objetivo y meta logran aportar con una evaluación del estado situacional y fomenta acciones, proyectos o modelos de negocios que generen una producción y consumo sostenible.

Por consiguiente, por un lado, el estado, encargado de formular lineamientos políticos, y las empresas, quienes destinan sus esfuerzos a la producción de alimentos y bebidas para consumo inmediato, deberán plantear políticas, estrategias y acciones que aporten soluciones para alcanzar una producción y consumo sostenible (Naciones Unidas, s.f.a), tal como se manifiesta en el objetivo 12; por otro lado, los consumidores, quienes evalúan y deciden qué adquirir, deberán reducir los desechos de los productos que usan y consumen, optando por opciones sostenibles como: no desperdiciar la comida, reducir el uso del plástico, fomentar el manejo adecuado de la energía en los aparatos electrodomésticos de casa, aumentar el reciclaje, comprar productos locales, entre otros (Naciones Unidas, s.f.c.).

Si bien, no es de extrañar, las diferentes aportaciones generadas sobre el desperdicio que se ha investigado a lo largo de estos últimos años (Marulanda-Grisales y Múnera-Ramírez, 2019), se resalta la contribución de Hernández (2018), quien plantea diferentes formas de evaluar el 
desperdicio alimentario: mediante un enfoque dominante de la eficiencia económica, un enfoque tradicional del derecho de los bienes y el enfoque moral que critica a los anteriores; haciendo referencia al impacto económico, ambiental y social que genera el desperdicio, han permitido formular acciones o medidas que mitigan esos impactos logrando construir un mundo más sostenible. No obstante, esas acciones que las empresas o los consumidores han considerado o deben considerar para evitar ese efecto pueden ser cuestionables sobre si han sido llevadas a cabo o no, o si son las correctas o no.

Ahora bien, para disminuir esos impactos negativos, para tal efecto, será necesario evaluar, si: 1) las políticas, estrategias y acciones aplicadas y consideradas para y por el sector de servicios de alimentos y bebidas, sobre todo de aquellas empresas de servicios gastronómicos y retails (comercio que se caracteriza por vender al por menor), están aportando y socializando sus actividades productivas y comerciales al cumplimiento del objetivo (ODS), y si existe, 2) una concientización por parte del consumidor sobre el producto que está adquiriendo de estos tipos de lugares.

Con base en lo anterior, el propósito y objetivo del presente documento es conocer las acciones que realizan tanto los establecimientos y empresas del sector de servicios de alimentos y bebidas para una producción responsable como del consumo responsable por parte de los consumidores de la ciudad de Quito, que adquieren de este tipo de empresas o de un retail.

En ese sentido, será necesario plantear un estudio desde el punto de vista de la empresa y el consumidor, los cuales atraviesan por diferentes etapas antes de tomar una decisión sobre qué producto o servicio vender o comprar. Por lo tanto, se plantea dos interrogantes iniciales que serán contestadas en los siguientes apartados: 1) ¿Qué dimensiones deben considerar las empresas de servicios gastronómicos para disminuir o erradicar el desperdicio de comida?, y 2) ¿Qué dimensiones se deben considerar para realizar un consumo responsable?

\section{Producción y consumo responsables}

Si bien, la producción y el consumo son fuerzas que aportan al impulso económico a nivel mundial, requieren, de manera continua, de varios recursos naturales que se encuentran en el medio ambiente. El uso inadecuado y excesivo de estos pueden generar a futuro efectos destructivos sobre los sistemas de los que depende el desarrollo del planeta.

Es decir, mientras que, la producción sostenible considera, minimizar el uso de recursos naturales, materiales tóxicos y emisiones de residuos contaminantes durante el ciclo de vida de todos los productos que da la tierra naturalmente o de los que se elaboran en la industria (Tapia y Ministerio de Ambiente, 2014) disminuyendo el impacto en el medio ambiente en términos de eficiencia, planeación y control (Marulanda-Grisales y Múnera-Ramírez, 2019), el consumo sostenible busca cumplir y satisfacer las necesidades de las generaciones presentes y futuras con bienes y servicios que sean sostenibles económica, social y ambientalmente (Tapia y Ministerio de Ambiente, 2014).

Por decirlo en un lenguaje usual, en una esquina, representando a la producción sostenible, se encuentra: 1) el sector productivo agrícola, avícola, ganadero y pesquero, 2) las empresas que 
procesan y distribuyen alimentos y bebidas para consumo inmediato (Ministerio de Turismo del Ecuador, 2018) -micro, pequeñas, medianas (MiPyMES) y grandes tiendas y cadenas de supermercado (retail)- y 3) aquellas que realizan actividades gastronómicas como: restaurantes, cafeterías, tanto para comer a domicilio y para llevar, catering para eventos, comedores o cafeterías en fábricas, oficinas, hospitales o escuelas, bares, cervecerías y pubs, por mencionar algunos (ISIC 56 - United Nations Environment Programme, 2021); y en la otra esquina, representando al consumo sostenible, 4) el cliente final o el consumidor, quien requiere satisfacer diversas necesidades y deseos por medio de la obtención de productos (alimentos, bebidas u otros elementos esenciales para vivir) y servicios, provenientes de estos tipos de empresas (Leyva-Hernández, Toledo-López, y Hernández-Lara, 2021).

Según la United Nations Environment Programme (UNEP), en sus estudios sobre el índice de desperdicio de alimentos en el 2021 en cuanto a la producción y consumo de alimentos se refiere, manifiestan que, de los 931 millones de toneladas que se genera de desperdicio de comida alrededor del mundo, el $26 \%$ proviene del sector de servicios de alimentos y bebidas o de servicios gastronómicos (food service), los cuales proceden de entornos donde los alimentos se consumen en cantidades sustanciales fuera de casa; el 13\% del comercio minorista o supermercados (retail) (United Nations Environment Programme, 2021); y el 61\% de los hogares (households and families - United Nations Statistics Division, 2020).

Solo por mencionar algunos casos, de acuerdo a las referencias socializadas por las Naciones Unidas en este mismo estudio, (United Nations Environment Programme, 2021), la estimación de desperdicio promedio en los hogares (households) de Estados Unidos es de 19359 951 toneladas - $59 \mathrm{~kg}$ de desperdicio por persona al año ( $\mathrm{kg} /$ cápita / año); en España 616037 toneladas - $77 \mathrm{~kg}$ por persona al año; o a nivel de región, en América Latina y el Caribe con un promedio de 73.5 (kg / cápita / año) se destaca México con 11979364 toneladas - 94 (kg / cápita / año) y Brasil 12578308 - 60 (kg / cápita / año), por señalar algunos ejemplos (United Nations Environment Programme, 2021).

En Ecuador, específicamente, se estima que cada ciudadano desperdicia en promedio 72 kilogramos de alimentos al año (United Nations Environment Programme, 2021); al multiplicar por los 17,5 millones de habitantes proyectados de la población ecuatoriana (Instituto Nacional de Estadística y Censos -INEC-, 2013) da un desperdicio alrededor de 1.260 millones de kilos (Primicias, 2021).

En definitiva, si bien, los desperdicios de alimentos tienen un impacto negativo en muchos frentes: medio ambiente, seguridad alimentaria, estado nutricional, valor económico, disponibilidad y precio de los alimentos (Organización de las Naciones Unidas para la Alimentación y la Agricultura, 2015; Alaña, Capa, \& Sotomayor, 2017), será necesario, por parte de todos, identificar soluciones que minimicen esos impactos y disminuyan esas pérdidas.

\section{Disminución de pérdidas y desperdicios en el sector de servicios de alimentos y bebidas}

Tomando en consideración el Objetivo de Desarrollo Sostenible (ODS) número 12 y de éste la meta 3 anteriormente mencionada, será una prioridad, del sector de servicios de alimentos y bebidas y de los consumidores que adquieren productos procedentes de estos establecimientos y 
de pequeñas, medianas, grandes cadenas de supermercado o tiendas, buscar soluciones que logren producir y consumir de forma responsable como, por ejemplo:

- Planificar y controlar las estrategias, procesos y acciones que se realicen a lo largo de la cadena productiva en sus distintas fases: 1) producción agrícola, avícola, ganadera y pesquera, relacionadas con el sector de servicios de alimentos y bebidas; aquí, los alimentos que nunca se consumen representan un desperdicio de recursos, como la tierra, el agua, la energía, las semillas y otros insumos utilizados en la producción, 2) manejo y almacenamiento de productos, 3) procesamiento de alimentos, 4) distribución al cliente final o intermediario (mayorista, minorista, detallista), 5) venta por retail -micro pequeñas, medianas y grandes tiendas y cadenas de supermercado-, y 6) consumidor (Organización de las Naciones Unidas para la Alimentación y la Agricultura, 2016).

- En los establecimientos de servicios gastronómicos sostenibles del sector de servicios de alimentos y bebidas (food service) se debe enfocar procesos productivos en los distintos puntos de las cadena alimentaria que tienen responsabilidad directa con la pérdida y el desperdicio de alimentos; es decir, desde la producción hasta el consumo (compras, almacenamiento, transporte, manipulación de alimentos y técnicas aplicadas en la materia prima) (HLPE, 2014), por mencionar algunos ejemplos, está: priorizar la adquisición de productos frescos, locales y de temporada de la zona, proponer y aplicar buenas prácticas medioambientalmente sostenibles como: reducción de uso de recursos, reciclaje, gestión de energía, agua, residuos, compras, mermas (Prieto-Sandoval, Jaca, y Ormazabal, 2017; Montesdeoca-Calderón, Gil-Saura, y Ruiz-Molina, 2020), manejar adecuadamente la temperatura de adquisición, almacenamiento y cocción y buenas prácticas de manufactura, considerar una buena inversión en tecnología (equipos de cocina), optimizar proceso de elaboración, medir bien el tiempo de espera del cliente, sobre todo si se debe generar comida ya preparada y almacenada lista para servir (Organización de las Naciones Unidas para la Alimentación y la Agricultura, 2015), considerar el modelo de la regla de las tres erres (3R): reducir, reutilizar y reciclar, o dependiendo de la legislación de cada lugar, hasta donar (Sasot, 2018; Muñoz, 2021) y evaluar el lapso de tiempo en la movilización o transporte, entre la producción y el consumo, al existir productos frescos que pueden dañarse por efecto del calor que generen un descenso del contenido nutricional (HLPE, 2014). Según el Catastro de actividades turísticas emitido por el ministerio de Turismo en el 2021, en la ciudad de Quito existen 4480 establecimientos gastronómicos registrados como actividades turísticas en la provincia de Pichicha y 3818 en la ciudad de Quito (Ministerio de Turismo, 2021).

- En cuanto al comercio minorista o supermercados sostenibles (retail), será necesario: gestionar una inversión adecuada para la construcción, infraestructura y adquisición de equipos para la venta, realizar una constante y correcta gestión en mantenimiento, limpieza y desinfección en áreas de recepción, almacenamiento, venta, y despacho, exigir a los proveedores que los productos tengan los registros correspondientes, una rotación adecuada a partir de las fechas de fabricación y vencimiento, apoyar al productor local, considerar una infraestructura de transporte de alimentos de un punto a otro según las características de la materia prima, el etiquetado del producto debe contener la información necesaria de caducidad del producto con la finalidad de gestionar la existencia de 
inventarios, pero también proveer al usuario un tiempo de inocuidad alimentaria, además de retener al consumidor y proteger la reputación (HLPE, 2014). Según estudios realizados por Carvajal (2020), en Ecuador existe unas 130000 tiendas de abarrotes; en Quito 9426 locales con Licencia Metropolitana Única para el Ejercicio de Actividades Económicas (LUAE) que expenden alimentos y otros productos.

- A nivel de hogares sostenibles (households and families), como medidas de acción para disminuir esos indicadores, puede ser: atacar las causas relacionadas con los comportamientos y los hábitos de compra, preparación y consumo de alimentos, y evitar ser influenciado por las técnicas de comercialización que incurran en una mala decisión de compra (HLPE, 2014). Para mitigar esto se debe realizar una buena planificación del menú que se va a consumir en la semana y así adquirir los alimentos necesarios que se requieran para su desarrollo; comer de forma saludable, no comprar más de lo que realmente se va a utilizar, conocer cómo almacenar mejor la comida o preparar alimentos mediante adecuadas técnicas de cocción, y también considerar la regla de las tres erres (3R) (Sasot, 2018). De acuerdo a los resultados del Censo 2010 de población y vivienda del Ecuador, existen 727.838 hogares en la provincia de Pichincha (Instituto Nacional de Estadísticas y Censos, 2010); conformado por más de 2.6 millones de habitantes; de esta cifra el 87\% residen en el Cantón Quito (INEC, 2013).

\section{Procesos y actividades para una producción con responsabilidad}

Teniendo una idea más clara con lo anteriormente descrito, y con el fin de dar respuesta a la primera interrogante, ¿Qué dimensiones deben considerar las empresas de servicios gastronómicos para disminuir o erradicar el desperdicio de comida?; según Foladori y Tommasino (2000), referido por Alaña, Capa y Sotomayor (2017), esas dimensiones deberán ser considerados a partir de tres grandes ejes: 1) la sustentabilidad ecológica, la cual se construye sobre la dimensión ambiental, 2) la sustentabilidad social limitada, la cual se rige por los impactos sociales que se generan entorno a esta, y 3) la coevolución sociedad-naturaleza, la cual evalúa la relación que se genera entres dos dimensiones.

$\mathrm{Si}$ bien estos autores valoran los factores ambientales y sociales, como elementos importantes al momento de ejercer las funciones empresariales, dejan de lado otra dimensión importante, la económica. En ese aspecto, es fundamental sumar los efectos negativos que se generan en el desarrollo económico por consecuencia de la degradación del medio ambiente o por el aporte económico que influye a nivel social, al generar beneficios monetarios, no sólo a los propietarios de empresas o negocios, sino también, a trabajadores o comunidades por medio de fuentes de empleo y oportunidades laborales (Gallardo-Gordón y Galarza-Torres, 2019).

En síntesis, y manteniendo la misma ideología, y con el fin de identificar los criterios que permitan disminuir o erradicar el desperdicio de comida, se debe considerar tres dimensiones fundamentales: ambiental, económica y social (AES).

En cuanto a la primera dimensión, ambiental, se debe evaluar la contaminación y el cambio climático a partir de la elaboración de productos y servicios ecológicos (recursos relacionados con huella de carbono, gestión de residuos, etc.) (Tapia y Ministerio de Ambiente, 2014). Para ello, las 
empresas, sobre todo aquellas que prestan servicios de alimentos y bebidas, deben considerar el desarrollo de procesos y actividades que minimicen esos efectos negativos al medio ambiente y que contribuyan en la conservación de los recursos. En consideración a la información que se describe en el Registro Oficial 218 - Gestión integral en el consumo y producción sustentable a nivel nacional- de Ecuador, se contempla que, deben existir lineamientos políticos, estratégicos y acciones que orienten al consumo y producción sostenible donde el factor ambiental juega un papel fundamental en el sector productivo y comercial de una nación; entre estas se destacan: conservar los recursos ambientales estratégicos del Estado optimizando el uso de los servicios básicos, como uso eficiente del agua (Hernández, 2018), sobre todo en empresas que crean bebidas a base de este componente esencial, producir en forma limpia y sostenible, realizar programas de optimización de recursos, así como un manejo integral de los residuos, instrumentar procesos de eco-eficiencia y eco-etiquetado, e impulsar la educación, capacitación en consumo y producción sustentable (Tapia y Ministerio de Ambiente, 2014).

En relación a la segunda dimensión, económica, se deben optimizar recursos que puedan afectar a los ingresos de un negocio (implica el uso de prácticas económicamente rentables en materia prima e insumos relacionados con proveedores cercanos y eficiencia) (Prieto-Sandoval et al., 2017). Desde una postura económica, se trae a colación, las acciones que deben ser consideradas desde una visión a partir del modelo propuesto por la Economía Circular, donde implique: extraer, transformar, distribuir, usar y recuperar los materiales y la energía de productos y servicios obtenidos del medio ambiente (Prieto-Sandoval et al., 2017). Esto permitirá equilibrar la producción, uso y desecho (Hoyer et al., 2015) de los productos que se obtienen para consumo humano.

Finalmente, como tercera dimensión, en el eje social, el cual aborda una amplia gama de actividades a realizar por parte de una empresa desde considerar ambientes de trabajo seguros y saludables hasta programas de concientización ecológica (buenas prácticas relacionadas a la contratación del personal y trato al cliente) (Uribe-Macías, Vargas-Moreno y Merchán, 2018), se debe: ofrecer una calidad de vida laboral, capacitar al personal en materia de sostenibilidad, proponer diversas estrategias o acciones comerciales que muestren un compromiso social con la comunidad y grupos de interés, promover una oferta gastronómica saludable al consumidor (Horna, Tamara, Ochoa y Uribe, 2018).

En ese contexto, la tabla 1, muestra aquellas dimensiones y acciones, que las empresas y establecimientos de alimentos y bebidas deben considerar para garantizar una producción en cada una de estas tres dimensiones identificadas.

\section{Tabla 1}

Criterios de sostenibilidad en el sector de servicios de alimentos y bebidas

\begin{tabular}{ccc}
\hline Factor & Dimensión & Criterio \\
\hline $\begin{array}{c}\text { Producción } \\
\text { (F1) }\end{array}$ & Ambiental & $\begin{array}{l}\text { (A1) Conservar los recursos ambientales. } \\
\text { (A2) Producir en forma limpia y sostenible }\end{array}$ \\
& (A) & $\begin{array}{c}\text { (A3) Realizar programas de optimización de recursos, así como } \\
\text { un manejo integral de los residuos. }\end{array}$ \\
\hline
\end{tabular}




\begin{tabular}{|c|c|c|}
\hline Factor & Dimensión & $\begin{array}{ll}\text { Criterio } \\
\end{array}$ \\
\hline & & $\begin{array}{l}\text { (A4) Instrumentar procesos de Eco-eficiencia y eco-etiquetado } \\
\text { (A5) Impulsar la educación, capacitación en consumo y } \\
\text { producción sustentable }\end{array}$ \\
\hline & $\begin{array}{c}\text { Económica } \\
\text { (E) }\end{array}$ & $\begin{array}{l}\text { (E1) Adquirir alimentos que se han obtenido (extraer) mediante } \\
\text { métodos agrícolas respetuosos con el medio ambiente }\left(^{*}\right) \\
\text { (E2) Ofrecer materia prima procedente de un comercio justo } \\
\text { donde se promueva una relación comercial voluntaria y } \\
\text { justa entre productores y consumidores. } \\
\text { (E3) Utilizar (transformar) productos locales o de temporada } \\
\text { mediante el desarrollo de mejores prácticas tecnológicas e } \\
\text { innovaciones ecológicas para que tanto el producto o } \\
\text { servicio como su proceso se realicen de forma sostenible (*) } \\
\text { (E4) Distribuir una oferta gastronómica mediante empaques } \\
\text { biodegradables fabricados con materiales totalmente } \\
\text { naturales, no contaminantes, que pueden ser destruidos de } \\
\text { forma natural por los microorganismos como el sol, la } \\
\text { lluvia, el viento, la humedad, etc., }(*) \\
\text { (E5) Promover (usar) un modelo de "sistema de servicio del } \\
\text { producto", al ofrecer bienes tangibles a través de servicios } \\
\text { correctamente alineados con los canales de distribución y } \\
\text { comunicación con el cliente }(*) \\
\text { (E6) Recuperar residuos como un recurso biológico que puede } \\
\text { ser devuelto a la biosfera }(*)\end{array}$ \\
\hline & $\begin{array}{l}\text { Social } \\
\text { (S) }\end{array}$ & $\begin{array}{l}\text { (S1) Ofrecer una calidad de vida laboral mediante el incentivo } \\
\text { de empleos ecológicos, remuneración justa y condiciones } \\
\text { laborales. } \\
\text { (S2) Capacitar al personal en materia de sostenibilidad para de } \\
\text { esta manera fomentar hábitos sostenibles que ayuden a } \\
\text { reducir el desperdicio. } \\
\text { (S3) Proponer diversas estrategias o acciones comerciales que } \\
\text { muestren un compromiso social con la comunidad y grupos } \\
\text { de interés } \\
\text { (S4) Promover una oferta gastronómica saludable al consumidor } \\
\text { (S5) Fomentar un criterio de compra basado en sostenibilidad en } \\
\text { vista de la creciente demanda social, de los sectores } \\
\text { productivos y de alimentos. }\end{array}$ \\
\hline
\end{tabular}

Nota: (*) Acciones consideradas por la Economía Circular que implica: extraer, transformar, distribuir, usar y recuperar los materiales y la energía de productos y servicios (PrietoSandoval et al., 2017).

Fuente: Elaboración propia.

Frente a ese escenario, se propone los siguientes supuestos a ser comprobados:

- Hil= Las acciones ambientales por parte de las empresas están relacionadas con la producción responsable de los alimentos y bebidas. 
- Hi2= Las acciones económicas por parte de las empresas están relacionadas con la producción responsable de los alimentos y bebidas.

- Hi3= Las acciones sociales por parte de las empresas están relacionadas con la producción responsable de los alimentos y bebidas.

\section{Acciones de decisión ante un consumo con responsabilidad}

Con el fin de dar respuesta a la segunda interrogante, ¿Qué dimensiones se deben considerar para realizar un consumo responsable?; es necesario tomar en cuenta el comportamiento del consumidor gastronómico, el cual se lo puede abordar desde la óptica de las Ciencias del Comportamiento, sobre la base de la teoría psicológica, que busca entender la conducta de un individuo al momento de adquirir un bien o un servicio a partir de los enfoques cognitivo, social y conductual (Rivas e Ildefonso, 2013). En ese sentido, Hoyer et al. (2015) sostienen que un individuo atraviesa por 3 momentos o fases: antes, durante y después de realizar una compra; donde en cada una de ellas depende de lo que conoce, el grupo social en el que se relaciona y la conducta que tiene ante una marca, producto o servicio. Es decir, para un consumo responsable se debe estudiar tres dimensiones: los motivos por el cual un consumidor desea obtener un producto o servicio (adquisición), la razón por la cual usa esa compra (uso) y la forma en la que se deshacen de ella (desecho).

Con respecto a la adquisición de alimentos para el consumo humano, esta dependerá de lo que requiere la persona, la familia o el hogar con respecto a sus necesidades. Estos pueden provenir del entorno (tierra, recursos, etc.), de lo que uno recibe sin intercambio económico (donaciones, ayuda gubernamental, beneficencia, etc.) (Sasot, 2018), del comercio, intercambio, o de lo que se hereda (Latham, 2002). Con esto, la persona deberá evaluar: qué se puede adquirir, por qué, cómo, cuándo, dónde cuánto adquirir, con qué frecuencia, y por cuánto tiempo (Hoyer et al., 2015).

Posteriormente, entre los distintos usos que se pueden aplicar del producto adquirido (Hoyer et al., 2015), solo por mencionar los más comunes, se encuentran: como un alimento funcional para suministrar la energía necesaria a las células del cuerpo para el crecimiento, la restauración y el mantenimiento de los tejidos y órganos vitales por medio de los nutrientes (Torres, 2017; Aguirre, 2019), como un elemento para apoyar en actividades lúdicas (FernándezOliveras et al., 2016), como un elemento decorativo usado en diversos ambientes del hogar (decoraciones ornamentales), como elemento que aporta al diseño de ropa (Castillo y Ramírez, 2006) o joyería (Sarlak, 2019), como ingrediente para productos de higiene personal o cosméticos (Alcalde, 2007), alimento para mascotas, entre otros.

Cómo última etapa en el proceso de consumo es el desecho, y para ello se plantea como buena "regla" reducir en la medida de lo posible los desperdicios de todo aquello que se consume o compra (Muñoz, 2021), aquí, el considerar la regla de las 3R (reducir, reutilizar, reciclar) es fundamental (Sasot, 2018) para discernir la mejor decisión de esta actividad.

Tomando en cuenta, aquellos criterios de decisión planteados por (Hoyer et al., 2015), la tabla 2 muestra las dimensiones y acciones, que los consumidores consideran ante el consumo de alimentos y bebidas; mismos que deberían ser evaluados por parte del mismo individuo para generar un consumo responsable. 


\section{Tabla 2}

Criterios de decisión para consumo responsable

\begin{tabular}{|c|c|c|}
\hline Factor & Dimensión & Criterio \\
\hline \multirow{18}{*}{$\begin{array}{l}\text { Consumo } \\
\text { (F2) }\end{array}$} & \multirow{8}{*}{$\begin{array}{l}\text { Adquisición } \\
\text { (ADQ) }\end{array}$} & (ADQ1) ¿Qué adquirir? \\
\hline & & (ADQ2) ¿Por qué adquirir? \\
\hline & & (ADQ3) ¿Cómo adquirir? \\
\hline & & (ADQ4) ¿Cuándo adquirir? \\
\hline & & (ADQ5) ¿Dónde adquirir? \\
\hline & & (ADQ6) ¿Cuánto adquirir? \\
\hline & & (ADQ7) ¿Con qué frecuencia adquirir? \\
\hline & & (ADQ8) ¿Por cuánto tiempo debe adquirir? \\
\hline & \multirow{7}{*}{$\begin{array}{c}\text { Uso } \\
\text { (USO) }\end{array}$} & (USO1) Como alimento funcional \\
\hline & & (USO2) Para actividades lúdicas \\
\hline & & (USO3) Como ingrediente para productos de higiene \\
\hline & & personal o cosméticos \\
\hline & & (USO4) Para decoraciones ornamentales \\
\hline & & $\begin{array}{l}\text { (USO5) Como apoyo para el diseño de prendas de vestir y de } \\
\text { adorno }\end{array}$ \\
\hline & & (USO6) Otros usos \\
\hline & \multirow{3}{*}{$\begin{array}{l}\text { Desecho } \\
\text { (DES) }\end{array}$} & (DES1) Encontrar un nuevo uso (reusar) \\
\hline & & (DES2) Deshacerse de él de manera permanente (reciclar) \\
\hline & & (DES3) Disminuir el uso de recursos (reducir) \\
\hline
\end{tabular}

Fuente: Elaboración propia.

Frente a ese escenario, se propone los siguientes supuestos a ser comprobados:

- Hi4= El proceso de adquisición de un alimento por parte de los consumidores están relacionados con el consumo responsable.

- Hi5= El proceso de uso de un alimento por parte de los consumidores están relacionados con el consumo responsable.

- Hi6= El proceso de desecho de un alimento por parte de los consumidores están relacionados con el consumo responsable.

\section{Metodología}

\section{Muestra y recogida de datos}

Con el fin de lograr el objetivo propuesto, se diseñó y consideró una investigación de carácter cuantitativo con un diseño de tipo no experimental, descriptivo y transversal, que permita conocer sobre la producción de alimentos y bebidas como del consumo de manera responsable de los alimentos y bebidas destinados al consumo humano, procedentes del sector de servicios de alimentos y bebidas. Para esto, la investigación se realizó en Quito-Ecuador, con ayuda de dos 
encuestas diferentes, una para el factor producción y otra para el factor consumo, a partir de cuestionarios de forma auto administrada vía online (Computer-Assisted Web Interviewing -CAWI) (Luque, 2017), dónde la información se recopiló entre el 1 y 30 de agosto del 2021.

Para levantar la información, procedente de empresas y establecimientos relacionados con el sector de servicios de alimentos y bebidas, para el componente "producción", se identifica que, en la ciudad de Quito existen 3818 establecimientos registrados como actividades turísticas (Ministerio de Turismo, 2021) que producen y distribuyen alimentos y bebidas; por ello, se consideró, para un cálculo del tamaño de muestras finitas, con un nivel de confianza del $60 \%$ ( $\mathrm{z}=$ 1.65), una proporción esperada $(\mathrm{p})$ de $50 \%=0.5 ; \mathrm{q}=1-\mathrm{p}$ (en este caso $1-0.5=0$. 5) y una precisión (e) de 6\%, una muestra de 184 cuestionarios a levantar. Para su efecto, se trabajó mediante una técnica de muestreo no probabilístico de bola de nieve (McDaniel y Gates, 2016).

En cuanto al estudio relacionado con el componente "consumo", al existir en Quito, una población mayor a 2 millones de habitantes (INEC, 2010), donde su población económicamente activa (PEA) es del 60.2\% (INEC, 2018), se consideró, para un cálculo del tamaño de muestras infinitas, con una proporción esperada $(\mathrm{p})$ de $50 \%=0.5 ; \mathrm{q}=1-\mathrm{p}($ en este caso $1-0.5=0.5) \mathrm{y}$ una precisión (e) de 5\%, una muestra de 384 cuestionarios a levantar. Para su efecto, se trabajó mediante una técnica de muestreo no probabilístico de bola de nieve (McDaniel y Gates, 2016).

\section{Medición de las variables}

Para la medición de las variables, relacionadas con el componente "producción", se utilizaron en el instrumento 16 ítems con base en la revisión de la literatura distribuidos en tres dimensiones: ambiental (5), económica (6) y social (5), los cuales fueron extraídos de (Tapia y Ministerio de Ambiente, 2014; Prieto-Sandoval et al., 2017; Horna et al., 2018; Uribe-Macías et al., 2018).

Consecuentemente, para el factor "consumo", se contemplaron en el instrumento 17 ítems, distribuidos en 3 dimensiones, a partir de los criterios o fases que un cliente considera al momento de: adquirir (8), usar (6) y desechar (3), los productos, empaques o envases de los alimentos y bebidas, considerando la postura de (Hoyer et al., 2015), tal como se muestra en la Tabla 2.

En todos los casos se utilizaron escalas tipo Likert de 5 puntos con valores entre 1, totalmente en desacuerdo, a 5, totalmente de acuerdo. Una vez revisados los constructos para la utilización de las escalas, se procedió al levantamiento y posterior análisis y discusión de los resultados obtenidos en la investigación.

\section{Resultados y Discusión}

\section{Caracterización de la muestra del factor producción}

De acuerdo con la información levantada en relación al componente producción, la Tabla 3 presenta la distribución de la muestra según el tipo de establecimiento y la categoría a la que pertenecen. Se indica que, el mayor aporte se obtuvo de restaurantes con un $66 \%$ de participación, 
seguido de aquellos establecimientos que prestan servicio de banquetes o catering con un $17 \%$, cafeterías con el 14\%, establecimiento móvil (food truck) $2 \%$ y bares $1 \%$.

\section{Tabla 3}

Tipo de establecimiento y categoría

\begin{tabular}{|c|c|c|c|c|c|}
\hline Establecimiento & Frecuencia & Porcentaje & Categoría & Frecuencia & Porcentaje \\
\hline \multirow{5}{*}{ Restaurante } & \multirow{5}{*}{122} & \multirow{5}{*}{66} & Un tenedor & 27 & 15 \\
\hline & & & Dos tenedores & 22 & 12 \\
\hline & & & Tres tenedores & 40 & 22 \\
\hline & & & Cuatro tenedores & 18 & 10 \\
\hline & & & Cinco tenedores & 15 & 8 \\
\hline \multirow{3}{*}{ Cafetería } & \multirow{3}{*}{26} & \multirow{3}{*}{14} & Una taza & 15 & 8 \\
\hline & & & Dos tazas & 11 & 6 \\
\hline & & & Una copa & 0 & 0 \\
\hline \multirow[t]{2}{*}{ Bar } & \multirow[t]{2}{*}{2} & \multirow[t]{2}{*}{1} & Dos copas & 1 & 1 \\
\hline & & & Tres copas & 1 & 1 \\
\hline $\begin{array}{l}\text { Establecimiento móvil (food } \\
\text { truck) }\end{array}$ & 3 & 2 & Categoría única & 3 & 2 \\
\hline $\begin{array}{l}\text { Servicio de banquetes o } \\
\text { catering }\end{array}$ & 31 & 17 & Categoría única & 31 & 17 \\
\hline Total & 184 & 100 & & 184 & 100 \\
\hline
\end{tabular}

Fuente: Elaboración propia

En cuanto a la respuesta que se obtuvo de cada una de las variables consideradas en el cuestionario, la tabla 4, presenta los valores calculados de tendencia central de cada uno de los criterios contemplados por parte de las empresas.

En la dimensión ambiental se observa que la moda, para todos los casos, es de 5 puntos (equivalente a totalmente de acuerdo); no obstante, la acción de instrumentar procesos de ecoeficiencia y eco-etiquetado (A4) generó una media de 3.9, como uno de los valores más bajos e inferiores a 4 (equivalente a de acuerdo), seguido de realizar programas de optimización de recursos, así como un manejo integral de los residuos (A3) con una media de 4.0; como se puede contemplar, existen acciones por parte de las empresas, que, si bien tratan de generar una producción ambiental responsable, aún se mantienen actividades que deben ser mejoradas internamente.

En cuanto a la dimensión económica, generó para todos los casos una moda de 5; aun así, en la media se presentan valores muy dispersos e inferiores a 4 puntos; es decir, la cifra más baja (3.5) se presenta con la acción de distribuir una oferta gastronómica mediante empaques biodegradables fabricados con materiales totalmente naturales, no contaminantes, que pueden ser destruidos de forma natural por los microorganismos como el sol, la lluvia, el viento o la humedad (E4), esto quiere decir, que este tipo de actividad no es considerada por parte de las empresas que ofrecen servicios de alimentos y bebidas; muy similar, con un valor de 3.5, pasa al tratar de promover un modelo de "sistema de servicio del producto", que pretenda ofrecer bienes tangibles a través de servicios correctamente alineados con los canales de distribución y comunicación con el cliente (E5); esto demuestra que las empresas no hacen estudios de mercados adecuados o 
profundos que mejoren los procesos de producción y entrega. Otro valor a resaltar es aquel que generó una media de 3.9, adquirir alimentos que se han obtenido o extraído mediante métodos agrícolas respetuosos con el medio ambiente (E1); esto demuestra que una buena parte de las empresas estudiadas no consideran esta acción, lo que indica que las empresas gastronómicas trabajan con productos que han sido cultivados y alterados físicamente en cuanto a tamaño y tiempo de preservación que pueden afectar al medio ambiente.

A nivel social, los resultados difieren; solo dos generaron una moda de $5 \mathrm{y}$ tres una moda de 4; se observa que la media generada entre todos los casos es menor o igual a 4 puntos, siendo el más bajo, con un 3.8 la actividad relacionada con la capacitación al personal en materia de sostenibilidad para de esta manera fomentar hábitos sostenibles que ayuden a reducir el desperdicio (S2), le sigue, con una media de 3.9, el ofrecer una calidad de vida laboral mediante el incentivo de empleos ecológicos, remuneración justa y condiciones laborales (S1), proponer diversas estrategias o acciones comerciales que muestren un compromiso social con la comunidad y grupos de interés (S3) y promover una oferta gastronómica saludable al consumidor (S4). Y, con una media de 4.0, se obtuvo el fomentar un criterio de compra basado en sostenibilidad en vista de la creciente demanda social, de los sectores productivos y de alimentos (S5). En términos generales, la dimensión social, posee más acciones que no son contempladas por las empresas, en relación a sus otras dos dimensiones, esto quiere decir que, la producción responsable se limita más a las necesidades de la empresa que al consumidor final.

\section{Tabla 4}

Resultados descriptivos

\begin{tabular}{llccccc}
\hline Factor & Variable & Indicador & Moda & Porcentaje* & Media & $\begin{array}{c}\text { Desviación } \\
\text { estándar }\end{array}$ \\
\hline \multirow{4}{*}{ Ambiental } & A1 & 5 & 61.4 & 4.5 & 0.7 \\
& A2 & 5 & 79.3 & 4.7 & 0.6 \\
& A3 & 5 & 42.9 & 4.0 & 1.0 \\
& A4 & 5 & 38.0 & 3.9 & 1.0 \\
& A5 & 5 & 52.2 & 4.2 & 0.9 \\
& & E1 & 5 & 34.2 & 3.9 & 0.9 \\
& E2 & 5 & 41.3 & 4.0 & 0.8 \\
& & E3 & 5 & 52.7 & 4.2 & 0.9 \\
& & E4 & 5 & 31.0 & 3.5 & 1.2 \\
& & E5 & 5 & 32.1 & 3.7 & 1.0 \\
& & E6 & 5 & 42.9 & 4.0 & 1.1 \\
& & S1 & 4 & 34.8 & 3.9 & 1.0 \\
& Sconómica & S2 & 4 & 33.2 & 3.8 & 1.1 \\
& & S3 & 5 & 38.0 & 3.9 & 1.0 \\
& & S4 & 5 & 38.0 & 3.9 & 1.0 \\
& & S5 & 4 & 34.2 & 4.0 & 0.9 \\
\hline
\end{tabular}

Nota: $(*)$ Porcentaje de mayor respuesta generada en la moda

Fuente: Elaboración propia 


\section{Análisis de correlaciones del factor producción}

A continuación, se analizan las correlaciones ( $\mathrm{r}$ de Pearson) entre las variables de estudio de cada una de las dimensiones consideradas del factor producción.

Como se puede observar en la tabla 5, en primera instancia, todas las correlaciones son positivas, donde en la dimensión ambiental se contemplan datos estadísticamente significativos mayores a $(\mathrm{r}=0.5)$ entre la variable (A1) y la variable (A2) $(\mathrm{r}=0.604)$ y la variable (A3) y (A4) $(\mathrm{r}=0.550)$; lo que indica que las empresas tratan de conservar los recursos ambientales al producir en forma limpia y sostenible los productos que ofrecen en el mercado, de igual manera al realizar programas de optimización de recursos, así como un manejo integral de los residuos mediante procesos eco-eficientes y eco-etiquetado.

Por otro lado, en cuanto a la dimensión económica, las variables que poseen una relación entre sí, mayor a $(\mathrm{r}=0.5)$, se destaca: la variable $(\mathrm{E} 1)$ y la variable $(\mathrm{E} 2)(\mathrm{r}=0.651)$; la variable (E5) con (E6) $(\mathrm{r}=0.586)$ y también las variables $(\mathrm{E} 4)$ con la variable $(\mathrm{E} 5)(\mathrm{r}=0.513)$. Esto quiere decir que, de las empresas, que sí prefieren adquirir alimentos que han sido cultivados de forma amigable con el medio ambiente, ofrecen un producto que procede de un comercio justo y por lo tanto, el manejar un modelo de "sistema de servicio del producto" permite brindar un servicio correctamente alineado con los canales de distribución y comunicación con el cliente donde se tome en cuenta empaques biodegradables fabricados con materiales totalmente naturales, no contaminantes que puedan ser devueltos a la biosfera y así cumplir con las acciones consideradas por la Economía Circular.

En cuanto a la dimensión social, se presenta una relación positiva y significativa mayor a $(\mathrm{r}=0.6)$ entre las variables $(\mathrm{S} 4)$ y $(\mathrm{S} 5)(\mathrm{r}=0,635)$ y $(\mathrm{S} 1)$ y $(\mathrm{S} 2)(\mathrm{r}=0.622)$; lo que indica que, una empresa, a nivel externo, debe promover una oferta gastronómica saludable al consumidor que fomente un criterio de compra basado en sostenibilidad y, a nivel interno, es fundamental ofrecer una calidad de vida laboral al empleado mediante el incentivo de empleos ecológicos, remuneración justa y condiciones laborales donde la capacitación al personal, en materia de sostenibilidad, contribuya a fomentar hábitos sostenibles que logren disminuir el desperdicio.

\section{Tabla 5}

Matriz de correlaciones

\begin{tabular}{|c|c|c|c|c|c|c|c|c|}
\hline \multirow[t]{2}{*}{ Factor } & \multirow[t]{2}{*}{ Dimensión } & \multicolumn{7}{|c|}{ Correlación de Pearson } \\
\hline & & Indicador & A1 & A2 & A3 & A4 & A5 & \\
\hline \multirow{6}{*}{ Producción } & \multirow{5}{*}{ Ambiental } & A1 & 1 & 0.604 & 0.313 & 0.282 & 0.268 & \\
\hline & & A2 & 0.604 & 1 & 0.330 & 0.270 & 0.386 & \\
\hline & & A3 & 0.313 & 0.330 & 1 & 0.550 & 0.411 & \\
\hline & & A4 & 0.282 & 0.270 & 0.550 & 1 & 0.463 & \\
\hline & & A5 & 0.268 & 0.386 & 0.411 & 0.463 & 1 & \\
\hline & Económica & Indicador & E1 & E2 & E3 & E4 & E5 & E6 \\
\hline
\end{tabular}




\begin{tabular}{lccccccc}
\hline Factor & Dimensión & \multicolumn{7}{c}{ Correlación de Pearson } \\
\hline & E1 & 1 & 0.651 & 0.391 & 0.309 & 0.417 & 0.387 \\
& E2 & 0.651 & 1 & 0.458 & 0.378 & 0.458 & 0.406 \\
& E3 & 0.391 & 0.458 & 1 & 0.261 & 0.336 & 0.253 \\
& E4 & 0.309 & 0.378 & 0.261 & 1 & 0.513 & 0.475 \\
& E5 & 0.417 & 0.458 & 0.336 & 0.513 & 1 & 0.586 \\
& E6 & 0.387 & 0.406 & 0.253 & 0.475 & 0.586 & 1 \\
& Indicador & S1 & S2 & S3 & S4 & S5 & \\
\cline { 3 - 7 } & S1 & 1 & 0.622 & 0.564 & 0.493 & 0.497 & \\
& S2 & 0.622 & 1 & 0.574 & 0.391 & 0.568 & \\
& S3 & 0.564 & 0.574 & 1 & 0.526 & 0.496 & \\
& Social & S5 & 0.493 & 0.391 & 0.526 & 1 & 0.635 \\
& & 0.497 & 0.568 & 0.496 & 0.635 & 1 & \\
\hline & & & & & & &
\end{tabular}

Fuente: Elaboración propia

Cabe resaltar, la existencia de relaciones inferiores a $(r=0.3)$ entre variables que se encuentran solo en la dimensión ambiental ( 3 valores inferiores a $\mathrm{r}=0.3$ ) y la económica ( 2 valores inferiores a $r=0.3$ ). Esto manifiesta que, las decisiones que se consideren entre esas acciones no aportarían en la producción responsable o, al menos, no son significativos entre sí.

Por último, los resultados indican que, los impactos que generan las empresas en cuanto a producción responsable, se encuentran fuertemente asociadas a las decisiones relacionadas con la inversión que se requiere para la adquisición de sus recursos, esto les permite, transformar, distribuir y comercializar sus productos al consumidor final de una forma más eficiente para la empresa que sustentable.

\section{Análisis de regresiones del factor producción}

Luego comprobar la existencia significativa inter-relación en cada una de las variables que conforman las dimensiones ambiental, económica y social, se presenta los resultados del análisis de regresión lineal, según el modelo planteado para este estudio, tal como se puede observar en la tabla 6; esto permite determinar las relaciones causales entre lo que se desea alcanzar en el proceso con aquellas variables (acciones) que influyen para que se realice dicho proceso. De igual manera se logra identificar la dimensión e impacto que más afecta al desarrollo de una producción responsable.

\section{Tabla 6}

Regresión del factor producción

\begin{tabular}{|c|c|c|c|c|c|c|c|c|c|c|c|}
\hline \multirow[b]{2}{*}{ Dimensión } & \multicolumn{5}{|c|}{ Resumen de modelo } & \multicolumn{3}{|c|}{ ANOVA } & \multicolumn{3}{|c|}{$\begin{array}{c}\text { Coeficientes } \\
\text { estandarizados }\end{array}$} \\
\hline & $\mathbf{R}$ & $\begin{array}{c}\mathbf{R} \\
\text { cuadrado }\end{array}$ & $\begin{array}{l}\text { R cuadrado } \\
\text { ajustado }\end{array}$ & $\begin{array}{c}\text { Error } \\
\text { estándar } \\
\text { de la } \\
\text { estimación }\end{array}$ & Significancia & Regresión & gl & Sig. & & Beta & Sig.* \\
\hline $\begin{array}{l}\text { Ambiental } \\
\text { (a) }\end{array}$ & 0.620 & 0.385 & 0.371 & 0.574 & 0.00 & 36.948 & 4 & 0.000 & $\begin{array}{l}\text { A2 } \\
\text { A3 } \\
\text { A4 } \\
\text { A5 }\end{array}$ & $\begin{array}{c}0.560 \\
0.088 \\
0.095 \\
-0.027\end{array}$ & $\begin{array}{l}0.000 \\
0.228 \\
0.203 \\
0.696\end{array}$ \\
\hline Económico & 0.679 & 0.461 & 0.446 & 0.801 & 0.000 & 97.844 & 5 & 0.000 & E1 & 0.087 & 0.241 \\
\hline
\end{tabular}




\begin{tabular}{|c|c|c|c|c|c|c|c|c|c|c|c|}
\hline & \multicolumn{5}{|c|}{ Resumen de modelo } & \multicolumn{3}{|c|}{ ANOVA } & \multicolumn{3}{|c|}{$\begin{array}{c}\text { Coeficientes } \\
\text { estandarizados }\end{array}$} \\
\hline Dimensión & $\mathbf{R}$ & $\begin{array}{c}\mathbf{R} \\
\text { cuadrado }\end{array}$ & $\begin{array}{l}R \text { cuadrado } \\
\text { ajustado }\end{array}$ & $\begin{array}{c}\text { Error } \\
\text { estándar } \\
\text { de la } \\
\text { estimación }\end{array}$ & Significancia & Regresión & gl & Sig. & & Beta & Sig.* \\
\hline \multirow[t]{5}{*}{ (b) } & & & & & & & & & E2 & 0.119 & 0.128 \\
\hline & & & & & & & & & E3 & 0.091 & 0.147 \\
\hline & & & & & & & & & E4 & 0.244 & 0.000 \\
\hline & & & & & & & & & E6 & 0.365 & 0.000 \\
\hline & & & & & & & & & S1 & 0.33 & 0.651 \\
\hline \multirow{3}{*}{$\begin{array}{l}\text { Social } \\
\text { (c) }\end{array}$} & 0725 & 0525 & 0515 & 0630 & 0000 & 80881 & 4 & 0000 & S2 & 0.346 & 0.000 \\
\hline & 0.125 & 0.525 & 0.515 & 0.039 & 0.000 & 80.881 & 4 & 0.000 & S3 & 0.035 & 0.623 \\
\hline & & & & & & & & & S4 & 0.465 & 0.000 \\
\hline \multicolumn{12}{|c|}{$\begin{array}{l}\text { Nota: } \\
\text { (a)= Variable dependiente: A1; Predictores (variables independientes): A2, A3, A4, A5; } \\
\text { (b)= Variable dependiente: A5; Predictores (variables independientes): E1, E2, E3, E4, E6; } \\
\text { (c)=Variable dependiente: S5; Predictores (variables independientes): S1, S2, S3, S4 } \\
(*)=p<0.05\end{array}$} \\
\hline
\end{tabular}

Fuente: Elaboración propia

Tomando la siguiente postura de que el coeficiente de determinación ajustado, o R cuadrado ajustado, permite ver el grado de intensidad o efectividad que tienen las variables independientes en explicar la variable dependiente (cuanto más cerca de 1 se sitúe su valor, mayor será el ajuste del modelo a la variable que se está intentando explicar, o de forma inversa, cuanto más cerca de cero, menos ajustado estará el modelo y, por tanto, menos fiable será), y del mismo modo, que ésta también será la medida que define el porcentaje explicado por la varianza de la regresión en relación con la varianza de la variable explicada (donde manifiesta qué tan dispersos están los datos con respecto a la media, al decir que, los valores más altos representan mayor dispersión y los valores más bajos menor dispersión), se obtiene que:

El modelo explicativo de la dimensión ambiental, alcanzó una varianza del $37.1 \%$ (p= 0.000); lo que permite afirmar que, las acciones actuales realizadas por parte de una empresa, a nivel ambiental, contribuyen muy poco a la producción responsable sobre conservación de los recursos ambientales. En consideración al supuesto formulado, se aprueba Hil donde se manifiesta que las acciones ambientales por parte de las empresas están relacionadas con la producción responsable de los alimentos y bebidas.

Por otro lado, la dimensión económica, generó una varianza del 44.6\% (p=0.000), esto evidencia que, las acciones realizadas por parte de una empresa, a nivel económico, contribuyen considerablemente a la producción responsable sobre la gestión de un modelo de "sistema de servicio del producto" altamente económico para el negocio. En consideración al supuesto planteado, se aprueba Hi2 tomando en cuenta que las acciones económicas por parte de las empresas están relacionadas con la producción responsable de los alimentos y bebidas.

Finalmente, la dimensión social, presentó una varianza del 51.5\% ( $\mathrm{p}=0.000)$; esto demuestra que, las adecuadas acciones realizadas por parte de una empresa, a nivel social, contribuyen mejor al modelo, de lo que se puede observar en las otras dimensiones, al fomentar en el cliente un criterio de compra basado en una sostenibilidad. Tal como se demostró en su análisis correlacional. En ese sentido, se aprueba el supuesto Hi3 donde se manifiesta que las 
acciones sociales por parte de las empresas están relacionadas con la producción responsable de los alimentos y bebidas.

\section{Análisis prospectivo de los establecimientos de alimentos y bebidas}

- A nivel ambiental: en cuanto a esta dimensión, el escenario a futuro dependerá del control continuo de las políticas públicas y privadas en cuanto a los procesos de producción, distribución y almacenamiento que una empresa realiza para el desarrollo de alimentos y bebidas, sobre todo del uso adecuado y responsable de la vajilla, empaque, envase o recipiente que se destine para la trasportación, almacenamiento y consumo de alimentos; de no existir este tipo de acción se verá afectado directa e indirectamente el medio ambiente y los recursos que lo componen por el aumento de la contaminación del agua, suelo y aire.

- Económica: para esta dimensión, el escenario es muy desalentador, si bien existe un porcentaje representativo por parte de las empresas en desarrollar una producción responsable que aporta a mediano plazo a la economía de los sectores más vulnerables (MIPYMES) relacionados con este tipo de sector, existen empresas que se verán, o ya se ven afectadas por la pandemia, y por consiguiente el proceso de adquirir productos a partir de una economía de escala, donde la materia prima proviene de empresas gigantes, se contemplará como una salida favorable que perjudicará al pequeño productor local.

- Social: en cuanto a esta dimensión, la concientización en la gente sobre producir y vender alimentos de una forma más responsable es cada vez mayor, sobre todo entre las nuevas generaciones que toman en cuenta el nivel de importancia de cuidar el medio ambiente. En ese sentido, se evidenciarán un cambio positivo y sustancial entre aquellas empresas que se orientan más al mercado que aquellas que se orientan a la venta. En otras palabras, se presentará una oportunidad de crecimiento e innovación.

\section{Caracterización de la muestra del factor consumo}

De acuerdo con la información levantada en relación al componente consumo, la Tabla 7 presenta la distribución de la muestra según el perfil sociodemográfico al que pertenecen. Se muestra una participación del $36 \%$ por parte de los hombres y un $63 \%$ por parte de las mujeres. No obstante, solo el $1 \%$ no quiso informar el género al que pertenecen.

\section{Tabla 7}

Perfil de la muestra de estudio

\begin{tabular}{|c|c|c|c|c|c|c|}
\hline \multirow{3}{*}{ Consumidores } & \multicolumn{6}{|c|}{ Género } \\
\hline & \multicolumn{2}{|c|}{ Hombre } & \multicolumn{2}{|c|}{ Mujer } & \multicolumn{2}{|c|}{ No deseo contestar } \\
\hline & Frecuencia & $\%$ & Frecuencia & $\%$ & Frecuencia & $\%$ \\
\hline De 20 a 24 años & 35 & 9 & 55 & 14 & 2 & 1 \\
\hline De 25 a 29 años & 18 & 5 & 23 & 6 & 0 & 0 \\
\hline De 30 a 34 años & 19 & 5 & 18 & 5 & 0 & 0 \\
\hline De 35 a 39 años & 10 & 3 & 32 & 8 & 0 & 0 \\
\hline De 40 a 44 años & 10 & 3 & 32 & 8 & 0 & 0 \\
\hline De 45 a 49 años & 7 & 2 & 22 & 6 & 0 & 0 \\
\hline De 50 a 54 años & 18 & 5 & 30 & 8 & 0 & 0 \\
\hline
\end{tabular}




\begin{tabular}{lcccccc}
\hline \multicolumn{1}{c}{ Consumidores } & \multicolumn{3}{c}{ Género } \\
\cline { 2 - 6 } & Hombre & \multicolumn{2}{c}{ Mujer } & \multicolumn{3}{c}{ No deseo contestar } \\
\hline De 55 a 59 años & 7 & 2 & 14 & 4 & 0 & 0 \\
Más de 60 años & 16 & 4 & 16 & 4 & 0 & 0 \\
\hline Total & 140 & 36 & 242 & 63 & 2 & 1 \\
\hline Empleado de empresa pública & 17 & 4 & 27 & 7 & 0 & 0 \\
Empleado de empresa privada & 50 & 13 & 85 & 22 & 0 & 0 \\
Propietario de empresa & 27 & 7 & 32 & 8 & 0 & 0 \\
Estudiante & 33 & 9 & 58 & 15 & 2 & 1 \\
No tengo trabajo & 23 & 6 & 48 & 13 & 0 & 0 \\
\hline
\end{tabular}

Nota: Resultados sobre la base de 384 personas

Fuente: Elaboración propia

En cuanto a la respuesta que se obtuvo de cada una de las variables consideradas en el cuestionario, la tabla 8, presenta los valores calculados de tendencia central de cada uno de los criterios contemplados por parte de los consumidores.

Tabla 8

Resultados descriptivos

\begin{tabular}{|c|c|c|c|c|c|c|}
\hline Factor & Variable & Indicador & Moda & Porcentaje* & Media & $\begin{array}{c}\text { Desviación } \\
\text { estándar }\end{array}$ \\
\hline \multirow{17}{*}{ Consumo } & \multirow{8}{*}{ Adquisición } & ADQ1 & 5 & 57.6 & 4.4 & 0.7 \\
\hline & & ADQ2 & 5 & 57.3 & 4.4 & 0.7 \\
\hline & & ADQ3 & 5 & 52.6 & 4.3 & 0.7 \\
\hline & & ADQ4 & 5 & 44.2 & 4.1 & 0.9 \\
\hline & & ADQ5 & 5 & 49.7 & 4.2 & 0.8 \\
\hline & & ADQ6 & 5 & 48.7 & 4.2 & 0.8 \\
\hline & & ADQ7 & 5 & 53.6 & 4.3 & 0.8 \\
\hline & & ADQ8 & 5 & 40.6 & 4.0 & 0.9 \\
\hline & \multirow{6}{*}{ Uso } & USO1 & 3 & 31.8 & 3.7 & 1.0 \\
\hline & & USO2 & 5 & 21.9 & 3.0 & 1.4 \\
\hline & & USO3 & 2 & 25.3 & 2.7 & 1.3 \\
\hline & & USO4 & 5 & 32.6 & 3.3 & 1.4 \\
\hline & & USO5 & 5 & 38.0 & 3.5 & 1.4 \\
\hline & & USO6 & 5 & 37.2 & 3.4 & 1.4 \\
\hline & \multirow{3}{*}{ Desecho } & DES1 & 5 & 36.5 & 3.8 & 1.1 \\
\hline & & DES2 & 5 & 41.1 & 3.9 & 1.1 \\
\hline & & DES3 & 5 & 49.0 & 4.2 & 0.8 \\
\hline
\end{tabular}

Nota: (*) Porcentaje de mayor respuesta generada en la moda

Fuente: Elaboración propia

Como se puede observar, un gran porcentaje de los encuestados respondió, con una moda de 5, equivalente a totalmente de acuerdo, un adecuado proceso de adquisición del producto; no obstante, estas cifras se encuentran en un promedio de respuesta del $40.6 \%$ al $57.6 \%$. En cuanto a la dimensión uso, las personas manifiestan que destinan esos productos a otras acciones y por consiguiente los valores que se muestran son muy dispersos; si bien existe una moda de 5, en cuatro de los indicadores que conforman esta dimensión, el que más sobre sale es el USO1 y el USO3; esto quiere decir que la gente no conoce qué aportes nutricionales brindan los alimentos que consume o que lo utilizan como un producto para higiene personal o para tratamiento de la 
piel. Finalmente, entre las variables relacionadas con el desecho, en ninguna alcanzó un porcentaje de respuesta para una moda de 5 mayor al $50 \%$, por lo que las demuestra que las personas no tienen un proceso adecuado de los residuos o productos una vez consumidos.

\section{Análisis de correlaciones del factor consumo}

Consecuentemente se presentan los resultados obtenidos en cuanto al análisis referentes a las correlaciones existentes ( $\mathrm{r}$ de Pearson) entre las variables de estudio planteadas en cada una de las dimensiones consideradas del factor consumo.

Como se puede observar en la tabla 9, en primera instancia, todas las correlaciones son positivas en la dimensión adquisición y desecho, a diferencia de uso; esto se debe a que posee ítems formulados en forma negativa y uno en positiva. En síntesis, en la dimensión adquisición se contemplan siete datos estadísticamente significativos mayores a $(\mathrm{r}=0.6)$, siendo el más alto entre ellos la variable (ADQ2) y la variable (ADQ3) $(r=0.702)$; esto indica que el consumidor sabe por qué debe adquirir un producto proveniente de un establecimiento gastronómico y cómo lo puede obtener; de esta forma, se corrobora su relación entre las variables (ADQ1) y (ADQ2) (r =0.687), y las variables (ADQ1) y (ADQ3) $(r=0.669)$, cuyo fundamento se sustenta en el conocimiento de lo que se desea adquirir. Por otro lado, la relación existente entre las variables (ADQ3) y (ADQ4) $(\mathrm{r}=0.609),(\mathrm{ADQ} 4)$ y $(\mathrm{ADQ} 6)(\mathrm{r}=0.600)$, (ADQ6) y (ADQ7) $(\mathrm{r}=0.684)$, y (ADQ7) y (ADQ8) $(\mathrm{r}=0.618)$ complementan el proceso de adquisición que se debe realizar sobre un consumo responsable. A pesar que se pueden observar relaciones estadísticamente significativas entre sus variables, solo permite tener una perspectiva más clara del comportamiento que se efectúa como primera fase para alcanzar un consumo responsable. Por consiguiente, es necesario también entender la relación existente en las dos fases posteriores, uso y desecho.

En cuanto a la dimensión uso, la variable que mayor correlación generada es entre la variable (USO4) y la variable (USO5) $(\mathrm{r}=0.693)$; lo que indica que las personas no consideran los alimentos como decoraciones ornamentales y para el diseño de prendas de vestir y de adorno, pero si lo consideran en otras alternativas como en manualidad, para higiene personal, o como alimento para la mascota, lo que puede afectar a cumplir la meta de realizar un consumo responsable. Por otro lado, las relaciones existentes en la dimensión desecho generan cifras muy bajas, menores a $(r=0.5)$, lo que indica una escasa relación entre sus variables. Eso quiere decir que todavía falta para que las personas tomen conciencia en cuanto a la manera correcta de desechar los alimentos que compra y consume.

\section{Tabla 9}

Matriz de correlaciones

\begin{tabular}{llccccccccc}
\hline Factor & Dimensión & \multicolumn{10}{c}{ Correlación de Pearson } \\
\hline & & Indicador & ADQ1 & ADQ2 & ADQ3 & ADQ4 & ADQ5 & ADQ6 & ADQ7 & ADQ8 \\
\cline { 3 - 10 } & ADQ1 & 1 & 0.687 & 0.669 & 0.549 & 0.437 & 0.523 & 0.460 & 0.445 \\
Consumo & Adquisición & ADQ2 & 0.687 & 1 & 0.702 & 0.502 & 0.431 & 0.466 & 0.460 & 0.423 \\
& & ADQ3 & 0.669 & 0.702 & 1 & 0.609 & 0.553 & 0.540 & 0.562 & 0.471 \\
& & ADQ4 & 0.549 & 0.502 & 0.609 & 1 & 0.522 & 0.600 & 0.530 & 0.478 \\
& & ADQ5 & 0.437 & 0.431 & 0.553 & 0.522 & 1 & 0.581 & 0.531 & 0.427 \\
& & ADQ6 & 0.523 & 0.466 & 0.540 & 0.600 & 0.581 & 1 & 0.684 & 0.545 \\
\hline
\end{tabular}

Esta obra se comparte bajo la licencia Creative Common Atribución-No Comercial 4.0 International (CC BY-NC 4.0) Revista de la Universidad Internacional del Ecuador. URL: https://www.uide.edu.ec/ 


\begin{tabular}{|c|c|c|c|c|c|c|c|c|c|c|}
\hline \multirow{3}{*}{\multicolumn{2}{|c|}{ Dimensión }} & \multicolumn{9}{|c|}{ Correlación de Pearson } \\
\hline & & ADQ7 & 0.460 & 0.460 & 0.562 & 0.523 & 0.531 & 0.684 & 1 & 0.618 \\
\hline & & ADQ8 & 0.445 & 0.423 & 0.471 & 0.478 & 0.427 & 0.545 & 0.618 & 1 \\
\hline & \multirow{7}{*}{ Uso } & Indicador & USO1 & USO 2 & USO3 & USO4 & USO5 & USO6 & - & - \\
\hline & & USO1 & 1 & -0.311 & -0.325 & -0.409 & -0.284 & -0.202 & & \\
\hline & & USO2 & -0.311 & 1 & 0.496 & 0.50 & 0.450 & 0.300 & & \\
\hline & & USO3 & -0.325 & 0.496 & 1 & 0.551 & 0.475 & 0.317 & & \\
\hline & & USO4 & -0.409 & 0.550 & 0.551 & 1 & 0.693 & 0.434 & & \\
\hline & & USO5 & -0.284 & 0.450 & 0.475 & 0.693 & 1 & 0.442 & & \\
\hline & & USO6 & -0.202 & 0.300 & 0.317 & 0.432 & 0.442 & 1 & & \\
\hline & \multirow{4}{*}{ Desecho } & Indicador & DES1 & DES2 & DES3 & - & - & - & - & - \\
\hline & & DES1 & 1 & 0.484 & 0.367 & & & & & \\
\hline & & DES2 & 0.484 & 1 & 0.548 & & & & & \\
\hline & & DES3 & 0.367 & 0.458 & 1 & & & & & \\
\hline
\end{tabular}

Fuente: Elaboración propia

\section{Análisis de regresiones del factor consumo}

Luego comprobar la existencia significativa inter-relación en cada una de las variables que conforman las dimensiones del factor consumo (adquisición, uso y desecho), se presenta los resultados del análisis de regresión lineal, según el modelo planteado para este estudio, tal como se puede observar en la tabla 10; esto permite determinar las relaciones causales entre lo que se desea alcanzar como acción principal con aquellas variables que pueden afectar para que se realice dicha acción.

\section{Tabla 10}

Regresión del factor consumo

\begin{tabular}{|c|c|c|c|c|c|c|c|c|c|c|c|}
\hline \multirow[b]{2}{*}{ Dimensión } & \multicolumn{5}{|c|}{ Resumen de modelo } & \multicolumn{3}{|c|}{ ANOVA } & \multicolumn{3}{|c|}{$\begin{array}{c}\text { Coeficientes } \\
\text { estandarizados }\end{array}$} \\
\hline & $\mathbf{R}$ & $\begin{array}{c}\mathbf{R} \\
\text { cuadrado }\end{array}$ & $\begin{array}{l}\text { Recuadrado } \\
\text { ajustado }\end{array}$ & $\begin{array}{c}\text { Error } \\
\text { estándar } \\
\text { de la } \\
\text { estimación }\end{array}$ & Significancia & Regresión & gl & Sig. & & & Sig.* \\
\hline \multirow{7}{*}{$\begin{array}{l}\text { Adquisición } \\
\text { (a) }\end{array}$} & \multirow{7}{*}{0.758} & \multirow{7}{*}{0.574} & \multirow{7}{*}{0.566} & \multirow{7}{*}{0.472} & \multirow{7}{*}{0.000} & \multirow{7}{*}{113.385} & \multirow{7}{*}{7} & \multirow{7}{*}{0.000} & ADQ2 & 0.383 & 0.000 \\
\hline & & & & & & & & & ADQ3 & 0.260 & 0.000 \\
\hline & & & & & & & & & ADQ4 & 0.118 & 0.014 \\
\hline & & & & & & & & & ADQ5 & -0.017 & 0.706 \\
\hline & & & & & & & & & ADQ6 & 0.145 & 0.006 \\
\hline & & & & & & & & & ADQ7 & -0.056 & 0.288 \\
\hline & & & & & & & & & ADQ8 & 0.067 & 0.137 \\
\hline \multirow{4}{*}{$\begin{array}{l}\text { Uso } \\
\text { (b) }\end{array}$} & \multirow{4}{*}{0.433} & \multirow{4}{*}{0.188} & \multirow{4}{*}{0.177} & \multirow{4}{*}{0.916} & \multirow{4}{*}{0.000} & \multirow{4}{*}{73.360} & & \multirow{4}{*}{0.000} & USO2 & -0.091 & 0.116 \\
\hline & & & & & & & \multirow{3}{*}{5} & & USO3 & -0.122 & 0.038 \\
\hline & & & & & & & & & $\begin{array}{l}\text { USU4 } \\
\text { USO5 }\end{array}$ & $\begin{array}{r}-0.311 \\
0.039\end{array}$ & $\begin{array}{l}0.000 \\
0.564\end{array}$ \\
\hline & & & & & & & & & USO6 & -0.018 & 0.728 \\
\hline \multirow{2}{*}{$\begin{array}{l}\text { Desecho } \\
\text { (c) }\end{array}$} & \multirow{2}{*}{0.784} & \multirow{2}{*}{0.237} & \multirow{2}{*}{0.233} & \multirow{2}{*}{0.782} & \multirow{2}{*}{0.000} & \multirow{2}{*}{72.460} & \multirow{2}{*}{2} & \multirow{2}{*}{0.000} & DES1 & 0.189 & 0.000 \\
\hline & & & & & & & & & DES2 & 0.366 & 0.000 \\
\hline
\end{tabular}

Nota:

(a)= Variable dependiente: ADQ1; Predictores (variables independientes): ADQ2, ADQ3, ADQ4, ADQ5, ADQ6, ADQ7, ADQ8;

(b)= Variable dependiente: USO1; Predictores (variables independientes): USO2, USO3, USO4, USO5;

$(c)=$ Variable dependiente: DES3; Predictores (variables independientes): DES1, DES2

$(*)=p<0.05$

Fuente: Elaboración propia

Esta obra se comparte bajo la licencia Creative Common Atribución-No Comercial 4.0 International (CC BY-NC 4.0)

Revista de la Universidad Internacional del Ecuador. URL: https://www.uide.edu.ec/ 
En cuanto el modelo explicativo de la dimensión adquisición, alcanzó una varianza del $56.6 \%$ ( $p=0.000)$; lo que permite afirmar que, las adecuadas acciones realizadas por parte de los consumidores, contribuyen en algo, y de forma positiva, al adquirir los productos de una forma responsable. En ese aspecto, se aprueba $\mathrm{Hi} 4$ donde, los procesos de adquisición de un alimento por parte de los consumidores están relacionados con el consumo responsable.

Por otro lado, la dimensión uso, generó una varianza del 17.7\% ( $\mathrm{p}=0.000)$, un valor más cercano a cero; esto evidencia que, las acciones realizadas por parte de una persona en esta dimensión, no contribuyen de forma positiva al consumo responsable y, por lo tanto, los datos demuestran un ajuste menor al modelo considerado. Se acepta Hi5, por lo que se concluye que, los procesos de uso de un alimento por parte de los consumidores están relacionados con el consumo responsable pero que no están contribuyendo favorablemente al mismo.

Por último, la dimensión desecho, también presenta una varianza del 23.3\% ( $\mathrm{p}=0.000)$; esto señala que, las adecuadas acciones realizadas por parte de un consumidor también son muy cuestionables al realizar un consumo responsable; lo que afecta al criterio de compra basado en una sostenibilidad. Igualmente se concluye que se acepta el supuesto Hi6 al manifestar que el proceso de desecho de un alimento por parte de los consumidores está relacionado con el consumo responsable pero que no se genera de una forma adecuada.

Cabe señalar que, estos valores obtenidos, inferiores al 50\%, demuestra también que los seres humanos son simplemente más difíciles de predecir que, por ejemplo, los procesos físicos, tal como manifiesta (Minitab Editor blog, 2019); no obstante, aún se puede generar deducciones importantes acerca de la asociación entre los valores de los predictores y los cambios en el valor de respuesta obtenido.

\section{Análisis prospectivo de los consumidores}

- A nivel de adquisición: actualmente se observa en el consumidor un cambio favorable y responsable de los productos que está adquiriendo y consumiendo; el comportamiento del consumo de alimentos será más cultural y social, inclinados por una vida más saludable y responsable con el medio ambiente, no obstante, el nivel de conocimiento a nivel general sobre la forma adecuada de comprar, almacenar y desechar un alimento es muy baja, y por ello esto dependerá del nivel de información y formación que las empresas generan sobre ello.

- Uso: en cuanto al uso de alimentos de manera responsable se encuentra muy relacionado la dimensión anterior, donde el consumidor poco a poco aprenderá a utilizar, almacenar y transportar adecuadamente los alimentos y bebidas que va adquiriendo, esto también es debido a la concientización que se generó tras la pandemia del COVID-19.

- Desecho: gracias al tipo de publicidad e información que las grandes empresas que distribuyen o comercializan alimentos y bebidas a nivel de país se encuentran desarrollando constantemente sobre programas de reciclaje, permitirá generar nuevos hábitos y comportamientos de consumo y la forma correcta de desechar un alimento, envase o 
empaque que aporta favorablemente al entorno. Se observarán más puntos de acopio para reciclar y una concientización mayor dentro de casa.

\section{Conclusiones}

El propósito y objetivo del presente documento fue conocer las acciones que realizan tanto los establecimientos y empresas del sector de servicios de alimentos y bebidas para una producción responsable como del consumo responsable por parte de los consumidores de la ciudad de Quito, que adquieren de este tipo de empresas o de un retail. Los resultados que se obtienen de este estudio demuestran que la mayoría de empresas han centrado sus esfuerzos en la dimensión económica y que tratan de aportar ambientalmente al sistema en donde se desenvuelven; no obstante, dejan de lado o dan menor interés al aspecto social. De considerar este elemento, lograría equilibrar la gestión ideal en sus operaciones de manera sostenible. En cuanto al consumo responsable, por parte de una persona, el camino a la responsabilidad es largo y por lo tanto es necesario proponer estrategias y acciones que minimicen el desperdicio y el impacto negativo que pueda sufrir el medio ambiente, eso se evidencia en el uso de los productos que adquieren para su consumo, el cual también es utilizado en otras opciones.

Se concluye también que, a futuro existirá un cambio sustancial en el comportamiento de las empresas y el consumidor en cuanto a una producción y consumo responsable, lo que obliga a las empresas a replantearse la manera de producir, almacenar y distribuir sus productos, y a los clientes a identificad correctamente lo que compra y como lo desecha de una forma más responsable. Esto también impulsa el desarrollo de programas que se orienten a reducir, reutilizar y reciclar lo que sobra y no es consumible.

Finalmente, el análisis correlacional contribuye, en primera instancia, con información sobre la producción sostenible de los establecimientos o empresas que se dedican a este tipo de actividad en cuanto a sus puntos más débiles; esto permite tomar correctivos en relación a producción, comercio y distribución de sus alimentos y bebidas, y, como segundo punto, se puede entender el comportamiento de consumo de una persona que conoce qué alimentos adquirir, como usarlos y cómo desecharlos.

\section{Referencias Bibliográficas}

Aguirre, P. (2019). Alimentos funcionales entre las nuevas y viejas corporalidades. Revista de Antropología Iberoamericana, 14 (1),95-120. https://doi.org/10.11156/aibr.140106

Alaña, T., Capa, L. y Sotomayor, J. (2017). Desarrollo sostenible y evolución de la legislación ambiental en las MIPYMES del Ecuador. Universidad y Sociedad, 9(1), 91-99. http://rus.ucf.edu.cu/

Alcalde, M. (2007). Alimentos usados en formulación cosmética. Propiedades y aplicaciones. OFFARM, 26(3), 100-109. http://dica.minec.gob.sv/inventa/attachments/article/7639/Alimentos\%20y\%20cosm\%C3 \%83\%C2\%A9tica.pdf 
Bächler, R. (2017). El marco metodológico definido por el conductismo y heredado por la psicología cognitiva. Límite. Revista Interdisciplinaria de Filosofía y Psicología, 12(39), 76-83. https://revistalimite.cl/index.php/limite/article/view/79/79

Carvajal, A. (2020). SONDEO: ¿Cómo atienden las tiendas de barrio durante la cuarentena en Quito? El Comercio: https://www.elcomercio.com/actualidad/quito/empresasfuncionamiento-tiendas-barrios-covid19.html

Castillo, S. y Ramírez, I. (2006). Ensayo preliminar para la obtención de colorantes naturales a partir de especies vegetales comestibles [Tesis de grado. Universidad de El Salvador]. http://repositorioslatinoamericanos.uchile.cl/handle/2250/160976

Fernández-Oliveras, A., Virginia, M. y Oliveras, M. (2016). Estudio de una propuesta lúdica para la educación científica y matemática globalizada en infantil. Revista Eureka sobre Enseñanza y Divulgación de las Ciencias, 13(2), 373-383. https://www.redalyc.org/pdf/920/92044744010.pdf

Gallardo-Gordón, M. y Galarza-Torres, S. (2019). Relación entre la Responsabilidad Social Empresarial y el Desempeño Financiero en las Empresas Ecuatorianas que Cuentan con Informes de Sostenibilidad desde el Periodo 2014 al 2018. X-Pedientes Económicos, 3(7), 1-17. http://portal.amelica.org/ameli/jatsRepo/392/3921934010/3921934010.pdf

Hernández, I. (2018). La producción y consumo sostenible y la reducción del desperdicio alimentario como una de sus metas. Persona e Amministrazione, 1, 125-147. https://doi.org/10.14276/2610-9050.1512

HLPE. (2014). Las pérdidas y el desperdicio de alimentos en el contexto de sistemas alimentarios sostenibles. Un informe del Grupo de alto nivel de expertos en seguridad alimentaria y nutrición del Comité de Seguridad Alimentaria Mundial. Roma: HLPE. http://www.fao.org/3/i3901s/i3901s.pdf

Horna, E., Tamara, S., Ochoa, F. y Uribe, Y. (2018). Responsabilidad social en restaurantes de Miraflores, Lima. Rev. Investig. Univ. Le Cordon Bleu, 5(1), 33-42. https://doi.org/10.36955/RIULCB.2018v5n1.003

Hoyer, W., Maclnnis, D. y Pieters, R. (2015). Comportamiento del consumidor. México: Cengage Learning Editores.

Instituto Nacional de Estadística y Censos (INEC). (2010). Población y Demografía - Quito. https://www.ecuadorencifras.gob.ec/censo-de-poblacion-y-vivienda/

Instituto Nacional de Estadística y Censos (INEC). (2018). Encuesta nacional de empleo, desempleo y subempleo (ENEMDU). Indicadores laborales 2018. https://www.ecuadorencifras.gob.ec/documentos/web-inec/EMPLEO/2018/Marzo2018/032018_Presentacion_M_Laboral.pdf

Instituto Nacional de Estadística y Censos (INEC). (2013). INEC presenta sus proyecciones poblacionales cantonales. $\quad$ https://Www.ecuadorencifras.gob.ec/inec-presenta-susproyecciones-poblacionales-cantonales/

Instituto Nacional de Estadísticas y Censos. (2010). Resultados del Censo 2010 de población y vivienda en el Ecuador. https://www.ecuadorencifras.gob.ec/wp-content/descargas/Manulateral/Resultados-provinciales/pichincha.pdf

Latham, M. (2002). Mejoramiento de la seguridad alimentaria en el hogar. En Nutrición humana en el mundo en desarrollo. Colección FAO: Alimentación y nutrición N²9.

Leyva-Hernández, S., Toledo-López, A. y Hernández-Lara, A. (2021). Purchase Intention for Organic Food Products in Mexico: The Mediation of Consumer Desire. Foods, 10, 2-17. https://doi.org/10.3390/foods10020245 
Luque, T. (2017). Investigación de marketing 3.0. Madrid: Pirámide.

Marulanda-Grisales, N. y Múnera-Ramírez, R. (2019). Decisiones estratégicas de operaciones en la producción sostenible: análisis de tendencias en investigación. Revista Lasallista de Investigación, 16(1), 228-243. https://doi.org/10.22507/rli.v16n1a4

McDaniel, C. y Gates, R. (2016). Investigación de mercados. Cengage Learning.

Ministerio de Turismo del Ecuador. (2021). Consolidado Nacional de Actividades Turísticas. Quito.

Ministerio de Turismo del Ecuador. (2018). Acuerdo Ministerial N. 2018 - 053. Reglamento de Alimentos y Bebidas. Quito: Ministerio de Turismo.

Minitab Editor blog. (2019). Análisis de Regresión: ¿Cómo Puedo Interpretar el R-cuadrado y Evaluar la Bondad de Ajuste? https://blog.minitab.com/es/analisis-de-regresion-comopuedo-interpretar-el-r-cuadrado-y-evaluar-la-bondad-de-ajuste

Montesdeoca-Calderón, M., Gil-Saura, I. y Ruiz-Molina, M. (2020). ¿Cómo influyen las prácticas verdes y el manejo del desperdicio alimentario en el capital de marca de los restaurantes? Estudios Gerenciales, 36(154), 100-113. https://doi.org/10.18046/j.estger.2020.154.3349

Moscovici, S. (1988). Introducción: el campo de la psicología social. En Psicología Social Tomo I (págs. 17-37). Barcelona: Paidós.

Muñoz, H. (2021). Avances legislativos sobre prevención y reducción de pérdidas y desperdicios de alimentos en América Latina y el Caribe. FAO - Roma: Organización de las Naciones Unidas para la Alimentación y la Agricultura. https://doi.org/10.4060/cb2889es

Naciones Unidas. (s.f.a). Producción y consumo responsables: por qué son importantes. https://www.un.org/sustainabledevelopment/es/wpcontent/uploads/sites/3/2016/10/12_Spanish_Why_it_Matters.pdf

Naciones Unidas. (s.f.b). Objetivo 12: Garantizar modalidades de consumo y producción sostenibles. https://www.un.org/sustainabledevelopment/es/sustainable-consumptionproduction/

Naciones Unidas. (s.f.c.). La Guía de los vagos para salvar el mundo. https://www.un.org/sustainabledevelopment/es/takeaction/

Organización de las Naciones Unidas para la Alimentación y la Agricultura. (2015). SAVE FOOD: Iniciativa Mundial sobre la reducción de la pérdida y el desperdicio de alimentos. http://www.fao.org/3/i4068s/i4068s.pdf

Organización de las Naciones Unidas para la Alimentación y la Agricultura. (2016). Pérdidas y desperdicio de alimentos. http://www.fao.org/resources/infographics/infographicsdetails/es/c/414198/

Organización de las Naciones Unidas para la alimentación y la Agricultura. (s.f). Plataforma técnica sobre la medición y la reducción de las pérdidas y el desperdicio de alimentos. http://www.fao.org/platform-food-loss-waste/es/

Prieto-Sandoval, V., Jaca, C. y Ormazabal, M. (2017). Economía circular: Relación con la evolución del concepto de sostenibilidad y estrategias para su implementación. Memoria Investigaciones en Ingeniería, 2301-1106. https://dadun.unav.edu/bitstream/10171/53653/1/Economia_Circular.pdf

Primicias. (2021). En Ecuador se pierden 72 kilos de alimentos anuales por persona. https://www.primicias.ec/noticias/economia/ecuador-desperdicio-kilos-alimentosanuales/

Programa de las Naciones Unidas para el Desarrollo. (2021). Objetivos de Desarrollo Sostenible. https://www1.undp.org/content/undp/es/home/sustainable-development-goals.html 
Rivas, A. e Ildefonso, G. (2013). Comportamiento del consumidor; decisiones y estrategia de marketing. ESIC.

Robayo, O. (2010). El modelo de perspectiva conductual como alternativa para la interpretación del comportamiento del consumidor. Poliantea, 6(11), 189-210. https://journal.poligran.edu.co/index.php/poliantea/article/view/206/186

Salazar, D. (2020). Modelación de las estrategias de Marketing de servicios sobre el comportamiento del consumidor aplicado a restaurantes de lujo y primera categoría de la ciudad de Quito [Tesis de doctorado. Universidad Nacional de Rosario, Argentina]. http://rephip.unr.edu.ar/handle/2133/20672

Sarlak, N. (2019). El uso de plantas medicinales en joyería contemporánea [Tesis de maestría. Universidad Autónoma de Barcelona. España]. https://diposit.eina.cat/handle/20.500.12082/984

Sasot, G. (2018). La donación de alimentos a entidades con fines sociales y su papel en la lucha contra el desperdicio alimentario: análisis desde la vertiente jurídica [Tesis de grado]. Universitat de Lleida. Facultat de Dret, Economia i Turisme.

Tapia, L. y Ministerio de Ambiente. (3 de abril de 2014). Gestión integral consumo y producción sustentable a nivel nacional -Registro Oficial 218. https://www.ambiente.gob.ec/wpcontent/uploads/downloads/2018/06/Acuerdo-021.pdf

Torres, J. (2017). El alimento como producto de nutrición y placer: Reto actual de la industria y la academia. Vitae, 24(2), 9-10. https://doi.org/10.17533/10.17533/udea.vitae.v24n2(2)a01

United Nations Environment Programme. (2021). UNEP Food Waste Index Report 2021 (Índice de desperdicio de alimentos 2021). https://www.unep.org/es/resources/informe/indice-dedesperdicio-de-alimentos-2021

United Nations Statistics Division. (2020). Demographic and Social Statistics-Households and families-Standards and Methods. https://unstats.un.org/unsd/demographicsocial/sconcerns/family/\#docs

Uribe-Macías, M., Vargas-Moreno, Ó. y Merchán, L. (2018). La responsabilidad social empresarial y la sostenibilidad, criterios habilitantes en la gerencia de proyectos. Entramado, 14(1), 52-63. http://dx.doi.org/10.18041/entramado.2018v14n1.27107

Vargas, L. (1994). Sobre el concepto de percepción. Alteridades, 4(8), 47-53. https://alteridades.izt.uam.mx/index.php/Alte/article/view/588/586 